\title{
A Statistical Analysis of the Effects of a Uniform Minimum Drinking Age
}

Paul Hoxie

David Skinner

Transportation Systems Center

Cambridge, MA 02142

April 1987

Reprint

October 1988

Final Report

This document is available to the public through the National Technical Information Service, Springfield, Virginia 22161.

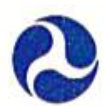

U.S. Department of Transportation

National Highway Traffic Safety Administration

Office of Research and Development

National Center for Statistics and Analysis

Washington, DC 20590 


\section{NOTICE}

This document is disseminated under the sponsorship of the Department of Transportation in the interest of information exchange. The United States Government assumes no liability for its contents or use thereof.

\section{NOTICE}

The United States Government does not endorse products of manufacturers. Trade or manufacturers' names appear herein solely because they are considered essential to the object of this report. 


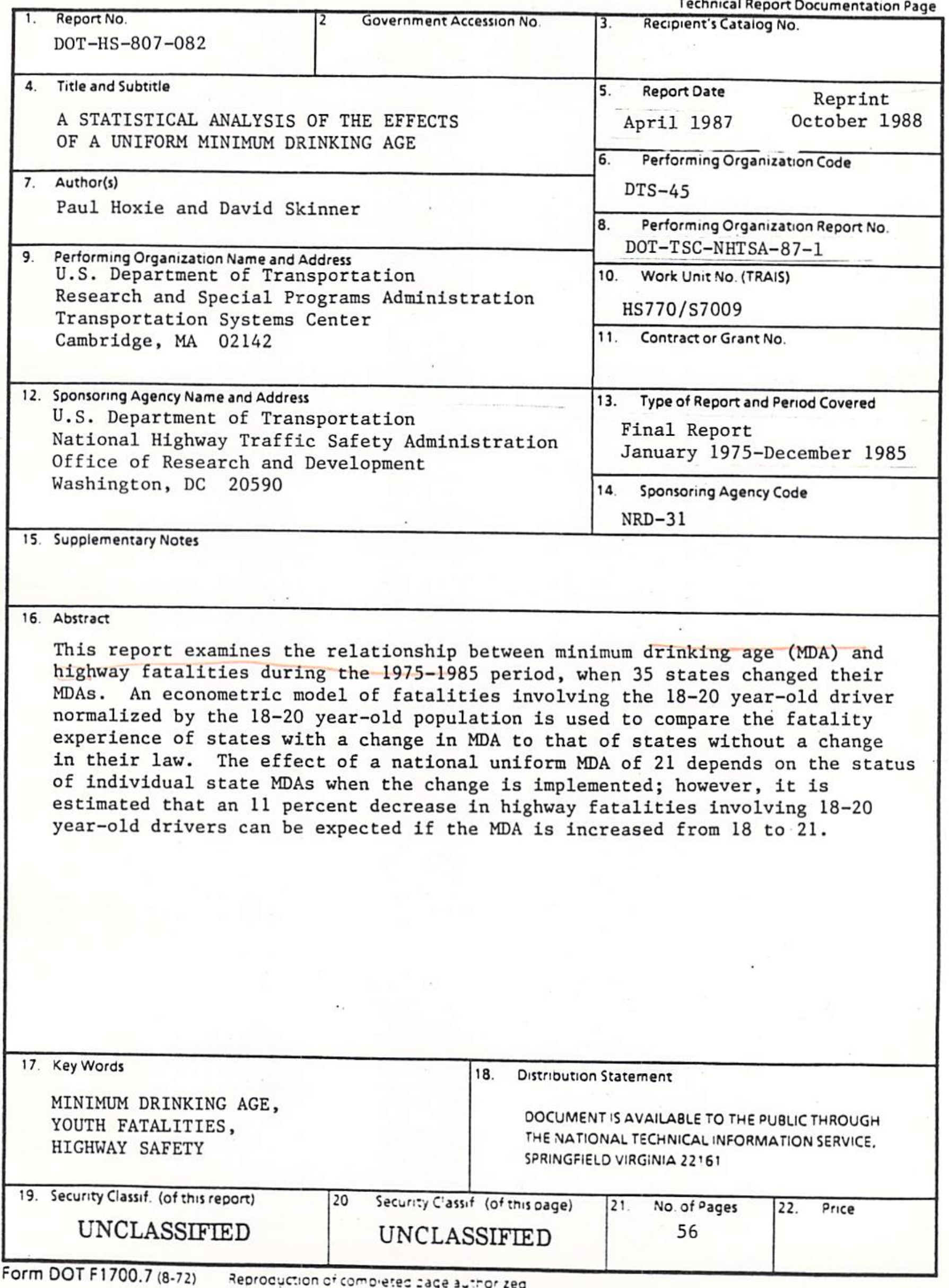





\section{PREFACE}

This study examines the experience of states which have changed their minimum drinking age during the 1975 to 1984 period and from this information develops an estimate of the effect of a uniform minimum drinking age of 21 on highway fatalities in the United States.

The work was performed by the U.S. Department of Transportation, Research and Special Programs Administration, Transportation Systems Center, Cambridge, Massachusetts under sponsorship of the U.S. Department of Transportation, National Highway Traffic Safety Administration, Office of Research and Development, Washington, DC.

The authors are grateful to James Hedlund, Chief of the Mathematical Analysis Divison of NHTSA's Center for Statistics and Analysis for suggesting and sponsoring the study and for the many valuable suggestions to improve it. The authors are also thankful for the suggestions made by E. Donald Sussman of TSC in his reviews of the work and to Robin Barnes for the tireless typing support which made the many drafts of the report possible. 


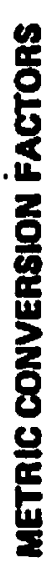
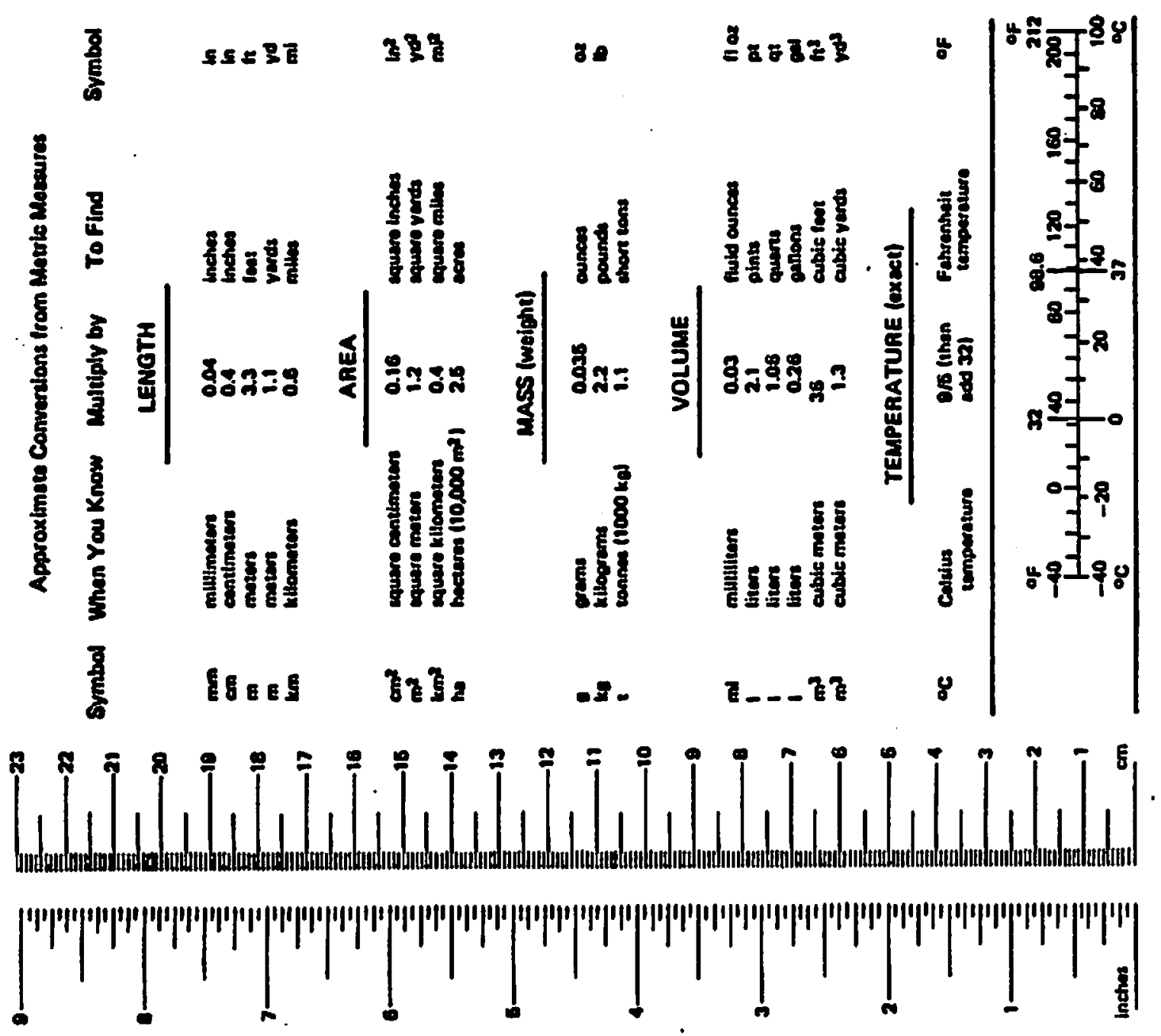

疍

ร8

EEE-D--ZZ :

章

을

$\stackrel{\circ}{\circ}$

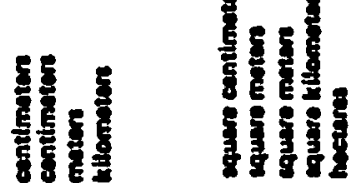

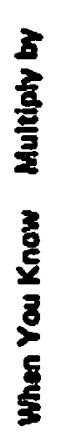

곤

รูำ

int IIII

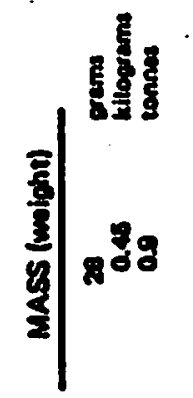

है

$5=$ श्रE

8

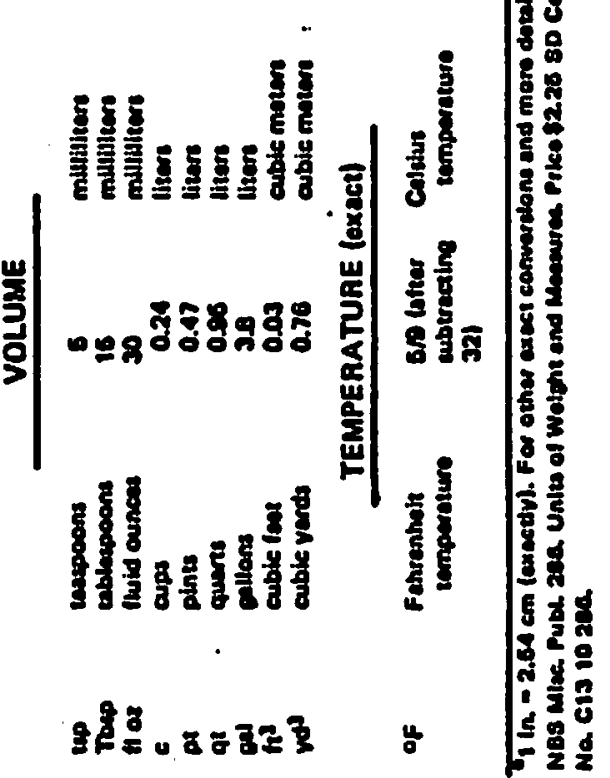


1.0 INTRODUCTION

2.0 BACKGROUND OF MINIMUM DRINKING AGE LEGISLATION

3.0 POSSIBLE INFLUENCE OF MINIMUM DRINKING AGE ON FATALITIES

4.0 METHODS

4.1 Selecting a Fatality Event

4.2 Adjusting for Population Changes

4.3 Methodology

4.4 Youth-Involved Fatality Model 15

4.5 Covariance Model

20

4.6 Estimating Lives Saved

22

5.0 RESULTS

24

5.1 Fatality Sensitivity to MDA Changes

5.2 Spillover Effects

5.3 Estimating Lives Saved 


\section{LIST OF TABLES}

$\underline{\text { Page }}$

Table E.1: Fatalities A ffected in 1984 by a Uniform MDA ix

Table 1: 1984 MDA: Purchase of Alcohol of Any A lcoholic Content 4

Table 2: Fatalities Involving 18-20 Year-Old Drivers 5

Table 3: MDA History 16

Table 4: Comparison of Fatalities Involving 18-20 Year-Old

Drivers With Those Involving Younger and Older Drivers 12

Table 5: Youth Population 13

Table 6: Econometric Model to Estimate Effects of Increases in MDA 16

Table 7: Concentration of 'A ge' Intervention Variable 19

$\begin{array}{ll}\text { Table 8: Control Variables } & 20\end{array}$

Table 9: Fatality Rates for 18-20 Year-Old Drivers By State for 1984

Table 10: Model I Results $\quad 26$

$\begin{array}{ll}\text { Table 11: Variables Used in MDA Models } & 27\end{array}$

$\begin{array}{ll}\text { Table 12: } \text { Model II Results } & 28\end{array}$

Table 13: Model III Results 29

Table 14: Model IV Results

Table 15: Model III on 14-17 Year-Old Drivers 33

Table 16: Model III on 14-20 Year-Old Drivers 34

Table 17: Model II on 21-23 Year-Old Drivers 36

Table 18: Statistical Test of A GE Using Model II on 21-23 Year-Old Drivers 37

Table 19: Effective Minimum Drinking A ge: Total and A djusted Fatalities 39

Table 20: Measured Lives Saved in 1984 By a Uniform MDA of 21 


\section{EXECUTIVE SUMMARY}

In 1984 there were 7,797 fatalities in highway accidents involving at least one driver between the ages of 18 and 20. This represents 17.6 percent of all highway fatalities. A large fraction of these fatal accidents involve alcohol. Raising the minimum drinking age promises a reduction in the number of fatalities involving drivers in this age group.

With this hope, Congress passed Public Law 98-363 which ties the provision of Federal Highway Trust $F$ unds to state passage of laws increasing the minimum drinking age to 21. The purpose of this study is to estimate how many lives are saved in states with a minimum drinking age above 18 and how many additional lives would be saved each year if all states adopted 21 as the minimum drinking age.

\section{Measuring the Effect of a Change in the Minimum Drinking A ge}

A number of states have increased the minimum drinking age (MDA) in the last ten years. The experience of these states can be used to measure the effect of a change in the minimum drinking age. The problem is to isolate the effect of the changes in MDA from all the other influences on highway fatalities. To illustrate this problem, consider a method which compares fatalities involving 18-20 year-old drivers in the state before the change in MDA to the same group of fatalities after the change. The problem with this approach is that many other forces could have caused the change as easily as the MDA change. For example, a change in the population of 18-20 year olds or a change in the economy which causes a change in the amount of driving by 18-20 year olds could easily have caused the observed change in fatalities.

The approach taken here attempts to minimize the influence of extraneous factors on the measured effect of a change in MDA. In this approach, the fatality experience of all states with a change in MDA is compared to the experience of all states without any change in MDA. Annual data between 1975 and 1984 on fatalities involving 18-20 yearold drivers per 18-20 year population for each state are used to calculate the effect. A pooled time-series, cross-sectional statistical method is used that accounts for the average state-to-state differences in 18-20 year-old fatality rates as well as for changes in the average 18-20 year-old fatality rate over time. Further, it accounts for factors which affect each state's fatality rate for drivers over 20 . This last factor helps account for many of the influences on the fatal accidents involvement 
rate of the 18-20 year-old drivers. In summary, the approach goes to great lengths to isolate the effect of changes in MDA from the numerous other factors which influence the fatality involvement rate of 18-20 year olds.

\section{Identifying the Affected Drivers}

In order to estimate the national effect of changes in MDA, from the reduction in fatalities involving affected drivers, we need to know how many 18-20 year-old drivers would be affected by the law change. This depends on the state drinking age laws in 1984. 3,292 of the 7,797 fatalities involving drivers in the 18-20 age group occurred in states where the MDA is already 21 . No reduction in fatalities can be expected in these states. Of the remaining 4,505 fatalities, 399 occurred in states where the minimum drinking age is 20 . If 18 year olds, 19 year olds and 20 year olds were each involved in one-third of these fatal accidents, then we could expect a change in the minimum drinking age from 20 to 21 to affect only about one-third of the 399 fatalities, 133, because only the fatalities involving 20 year-old drivers would be affected.

Similar reasoning leads us to estimate that two-thirds of the 3,065 fatalities involving drivers in the 18-20 age group in states with a current MDA of 19 might be affected by a change in the drinking age from 19 to 21 . This represents 2,043 fatalities. In the remaining states, where the MDA is currently 18, all of the 1,041 fatalities could be affected. These calculations are summarized in Table E.1 along with complimentary calculations of the fatalities affected by a hypothetical change in MDA to 18 . The change in MDA to 18 is used to measure how many lives are already being saved by MDAs above 18.

Table E.1 distinguishes between legal MDA and effective MDA. This distinction reflects the fact that states often permit people who can legally drink under the existing law to continue to drink under the new law. So, if a state changed its MDA from 18 to 21 on January 1, 1983 and this "grandfather" clause was included in the new law, then at the beginning of 1984,19 and 20 year olds could still drink in that state, but fewer and fewer 19 year olds could drink in the state as the year progressed. When the law changing the MDA takes effect on a date other than January 1 , an additional adjustment is needed in the number of fatalities under each age group to reflect partial years. 
Table E.1: Fatalities Affected in 1984 by a Uniform MDA

In $\mathrm{S}$ tates Where The

Effective MDA Is:

21

20

19

18

TOTALS

\begin{tabular}{ccc}
$\begin{array}{c}\text { Total } \\
\text { Fatalities }\end{array}$ & $\begin{array}{c}\text { Fatalities } \\
\text { Affected } \\
\text { By MDA } \\
\text { Change to 21 }\end{array}$ & $\begin{array}{c}\text { Fatalities } \\
\text { Affected } \\
\text { By MDA } \\
\text { Change to 18 }\end{array}$ \\
\cline { 2 - 3 } 3,292 & 0 & $\begin{array}{r}3,292 \\
266\end{array}$ \\
3,069 & 133 & 1,022 \\
1,041 & 2,043 & 0 \\
\hline 7,797 & 1,041 & $-1,580$
\end{tabular}

Results

We found that a change in the MDA from 18 to 21 reduces fatalities involving the affected 18-20 year-old drivers by approximately 11 percent. This result is obtained from a model which accounted for over 85 percent of the variation in state, annual per capita fatalities. Further testing of the model demonstrated that it was very specific in isolating the effects of MDA changes. These results give us confidence in the estimated effect of changes in the MDA.

Using this estimate of the effect of a change in the MDA and the number of fatalities in states tabulated by current effective MDA from Table E.1, the estimated lives saved by changing to a MDA of 21 in 1984 would have been $.11 \times 3,217=354$.

If all states had a MDA of 18 in 1984, fatalities involving 18-20 year-old drivers would have been higher than the actual 7,797 by about .11 $\times 4,580=504$. So, the total national effect of having a MDA of 21 rather than 18 is 858 lives saved. Since many states have MDAs above 18 , much of this effect is already realized but approximately 354 additional lives could have been saved if all states had had a MDA of 21 in 1984.

What about the effects on younger and older drivers? Applying similar methods to measure the effect of a MDA increase from 18 to 21 on fatalities involving drivers 
between 14 and 18 years old revealed a slight reduction in fatalities but the measured effect was not statistically significant.

The results for older drivers were similar. A slight decrease in fatalities involving 2123 year-old drivers was revealed, but again this effect was not statistically significant. Only two states had enough experience with a change in drinking age to 21 to be used in calculating this effect, further experience of other states might reveal a reliable effect.

If all states had responded to the Federal Government's suggestion by passing laws which set the MDA at 21 , an additional 354 lives could have been saved in 1984. Further, PL 98-363 by penalizing states with MDAs below 21, ensures that the 1984 estimate of 504 lives saved (due to MDAs above 18) will not decrease. The 858 lives which are saved as a result of a change in MDA from 18 to 21 represent 1.9 percent of all highway fatalities in 1984. 


\subsection{INTRODUCTION}

PL 98-363 authorized the Secretary of Transportation to withhold Highway Trust Funds from any state allowing purchase or public consumption of any alcoholic beverage by a person less than 21 years old. The law applies to funds apportioned to states in fiscal year 1987. It is intended to influence all states not currently at the compliance age to raise their Minimum Drinking A ge (MDA) to 21 years old. The purpose of this study is to assess the effect a national, uniform MDA of 21 years old would have on total highway fatalities. That is, how many lives would be saved if those states which do not presently have a 21 year-old MDA, increased the MDA to that level? We focus on the effect of the uniform MDA on highway fatalities for two reasons. First, alcohol is involved in approximately one-half of all fatal highway accidents, so changes in the MDA are likely to have a significant effect on highway fatalities. Second, the Fatal Accident Reporting Systems (FARS) provides a high-quality, consistent series of fatal highway accident data from 1975 onward. This data permits analyses which would not be workable with the less complete and less consistent data series on all highway accidents. The study does not assess all the benefits which would result from a uniform $M D A$ of 21 . A uniform MDA will reduce non-fatal as well as fatal highway accidents. The injury and property damage associated with the highway accidents avoided by increasing the MDA to 21 is a substantial benefit. In assessing the total benefits of a uniform MDA of 21 , these other benefits must be added to the decrease in fatalities which is measured in this study.

The methodology used to estimate the effect of a national, uniform MDA of 21 is divided into two components. The first uses cross-section, time-series econometric models to estimate the percentage change in fatalities expected to result from increases in MDA. The second identifies the current MDA in all states so that the population affected by a uniform MDA can be determined. The estimated national effect of a uniform MDA applies the empirically estimated percentage change in fatalities to the affected population.

Obviously, if fatalities are not very sensitive to the MDA because young drivers can still obtain alcohol easily or if the states with most of the highway fatalities already have a MDA near or at 21 years old, then the uniform MDA will have a small national 
impact upon fatalities. But, if fatalities are very sensitive to MDA changes and many high fatality states have low MDAs, then a sizable impact could occur.

This study was supported by Mathematical Analysis Division (MAD) of NHTSA's National Center for $S$ tatistics and Analysis (NCSA). MAD suggested the topic and the FARS data used in the analysis are collected and maintained by NCSA.

Chapter 2.0 presents a brief history of MDA legislation. Chapter 3.0 discusses how the legislation might influence state highway fatality levels. Chapter 4.0 presents the methods used in this study to estimate the effect of a uniform MDA of 21 years old. Chapter 5.0 presents the results of our analysis; Chapter 6.0 our conclusions. 


\subsection{BACKGROUND OF MINIMUM DRINKING A GE LEGISLATION}

In 1984 a patchwork of MDA laws existed among the 50 states and D.C. The MDA, alcoholic content, and conditions of purchase and consumption varied widely. As shown in Table 1, 21 states had a MDA of 21 years old, 5 states had a MDA of 20 years old, 18 states had a MDA of 19 years old, and 7 states had a MDA of 18 years old. There appears to be a positive association between degree of industrialization and higher MDA. A good part of the benefit of a MDA of 21 has already occurred because many states are already at or near the 21 year-old age.

When Prohibition ended, most states in the United $\mathrm{S}$ tates established MDA laws for the purchase and public consumption of beverages of specific alcohol content. During the early 1970s many of those states which had established a 21 year-old MDA lowered it in response to social and political events. It was reasoned if 18 year olds could be drafted into the military and were eligible to vote in Federal elections (with passage of the 26 th A mendment in 1970), they should be able to purchase and publicly consume alcohol.

In the mid-1970's, feeling developed that the lower MDA might be a cause of the increase in 18-20 year-old, driver-involved fatalities. Table 2 shows this increase absolutely and relative to other age groups, although the increase in fatalities among older groups suggests that there are other factors behind the growth besides MDA. S tarting with Minnesota, in September of 1976, 28 states have increased their MDA, some as many as three times. Since 1974, no state has lowered its MDA. Now PL 98363 provides financial incentives for states to increase their MDA to 21 years old.

Not only does the MDA differ among states, but other aspects of the MDA laws do as well. The alcoholic content of beverages defined under the laws vary. The 'split' legislation of some states allows a younger age group to purchase beer and wine, but not distilled liquor. Places of purchase and consumption differ among states. When states increased their MDA in the period of this study, some did so by a gradual process, or 'grandfathering,' which allowed those people who had the legal right to drink at the time

of enactment to retain that right but did not allow people with birthdays after enactment the privilege of purchasing alcohol. 


\begin{tabular}{|c|c|c|}
\hline $\begin{array}{l}\text { Minimum } \\
\text { Drinking } \\
\text { Age in } 1984 \\
\end{array}$ & $\begin{array}{l}\text { Number } \\
\text { of S tates }\end{array}$ & States \\
\hline 21 & 21 & $\begin{array}{l}\text { A laska, A rkansas, California, Delaware, } \\
\text { Illinois, Indiana, Kentucky, Maryland, } \\
\text { Michigan, Missouri, Nevada, New Jersey, } \\
\text { New Mexico, North Dakota, Oklahoma, } \\
\text { Oregon, Pennsylvania, Rhode Island, } \\
\text { Tennessee, Utah, Washington }\end{array}$ \\
\hline 20 & 5 & $\begin{array}{l}\text { Connecticut, Maine, Massachusetts, } \\
\text { Nebraska, New Hampshire }\end{array}$ \\
\hline 19 & 18 & $\begin{array}{l}\text { Alabama, Arizona, Florida, Georgia, Idaho, } \\
\text { Iowa, Minnesota, Montana, New York, North } \\
\text { Carolina, Ohio, South Carolina, South } \\
\text { Dakota, Texas, Virginia, West Virginia, } \\
\text { Wisconsin, Wyoming }\end{array}$ \\
\hline 18 & 7 & $\begin{array}{l}\text { Colorado, District of Columbia, Hawaii, } \\
\text { Kansas, Louisiana, Mississippi, Vermont }\end{array}$ \\
\hline
\end{tabular}


Table 2: Fatalities Involving 18-20 Year-Old Drivers

$\begin{array}{cccccc}\text { Year } & \begin{array}{c}\text { Fatalities } \\ \text { Involving } \\ \text { 18-20 Year- } \\ \text { Old Drivers }\end{array} & \begin{array}{c}\text { Percent of } \\ \text { Total }\end{array} & \begin{array}{c}\text { All Other } \\ \text { Fatalities }\end{array} & \begin{array}{c}\text { Percent of } \\ \text { Total }\end{array} & \text { Total } \\ 1975 & 8,996 & 20.2 & 35,529 & 79.8 & 44,525 \\ 1976 & 9,512 & 20.9 & 36,011 & 79.1 & 45,523 \\ 1977 & 10,108 & 21.1 & 37,770 & 78.9 & 47,878 \\ 1978 & 10,692 & 21.2 & 39,639 & 78.8 & 50,331 \\ 1979 & 10,551 & 20.7 & 40,542 & 79.3 & 41,093 \\ 1980 & 10,137 & 19.8 & 40,954 & 80.2 & 51,091 \\ 1981 & 9,160 & 18.6 & 40,141 & 81.4 & 49,301 \\ 1982 & 7,976 & 18.1 & 36,149 & 82.0 & 43,945 \\ 1983 & 7,445 & 17.5 & 35,144 & 82.5 & 42,589 \\ 1984 & 7,797 & 17.6 & 36,444 & 82.4 & 44,241\end{array}$

In this study, changes in state MDAs which occurred between 1975 and 1984 are used to estimate empirically the percentage changes in fatalities which are expected to result from further changes in MDA. As this brief history suggests, the empirical estimation is complex and requires careful definition of MDA with respect to alcohol content or beverages covered and careful accounting of when the population is affected in each state. Table 3 provides the basic information about state MDA laws used in this study. 


\begin{tabular}{|c|c|c|c|}
\hline State & $\begin{array}{c}\text { MDA Change and Year } \\
\text { of Last Change } \\
\text { Pre-1975 }\end{array}$ & $\begin{array}{c}\text { MDA Change and Year } \\
\text { of Change During } \\
\text { the Study Perlod } \\
1975-84\end{array}$ & $\begin{array}{l}\text { Grandfather } \\
\text { Clause for } \\
\text { Last Change In } \\
\text { Study Period } \\
\end{array}$ \\
\hline A labama & $21-19(1970)$ & -- & \\
\hline A laska & $19(N / A) * *$ & $19-21(10 / 26 / 83)$ & YES \\
\hline Arizona & $21-19$ (1972) & - & \\
\hline Arkansas & $21(1925)$ & $\cdots$ & \\
\hline California & 21 (1933) & $\cdots$ & \\
\hline Colorado & $18 / 21 *(1945)$ & $\cdots$ & \\
\hline Connecticut & $21-18(1972)$ & $\begin{array}{l}18-19(7 / 1 / 82) \\
19-20(10 / 1 / 83)\end{array}$ & $\begin{array}{l}\text { NO } \\
\text { NO }\end{array}$ \\
\hline Delaware & $20(N / A)$ & $20-21(13 / 31 / 83)$ & YES \\
\hline $\begin{array}{l}\text { District } \\
\text { of Columbia }\end{array}$ & $18 / 21 *(1934)$ & $\cdots$ & \\
\hline Florida & $18(N / A)$ & $18-19(10 / ? / 83)$ & No \\
\hline Georgia & $18(N / A)$ & $\begin{array}{l}18-19(9 / ? / 80) \\
19-20(9 / 30 / 84)\end{array}$ & $\begin{array}{l}\text { No } \\
\text { NO }\end{array}$ \\
\hline Hawail & $21-18(1972)$ & $\cdots$ & \\
\hline Idaho & $21-19(1972)$ & -- & \\
\hline Illinois & $21-19 / 21 *(1973)$ & $19 / 21 *-21(1 / 1 / 80)$ & No \\
\hline Indiana & $21(1934)$ & -- & \\
\hline Lowa & $21-18(1972)$ & $18-19(7 / ? / 78)$ & YES \\
\hline Kansas & $18 / 21 *(1949)$ & -- & \\
\hline Kentucky & 21 (1938) & - & \\
\hline Louisiana & $18(1948)$ & -- & \\
\hline
\end{tabular}

* Split legislation, first age corresponds to 3.2 beer or beer and wine, second age is for distilled liquors.

**(N/A - Not A vailable) 
Table 3: MDA History (cont.)

\begin{tabular}{|c|c|c|c|}
\hline State & $\begin{array}{c}\text { MDA Change and Year } \\
\text { of Last Change } \\
\text { Pre-1975 }\end{array}$ & $\begin{array}{l}\text { DA Change and Year } \\
\text { of Change During } \\
\text { the Study Period } \\
1975-84 \\
\end{array}$ & $\begin{array}{l}\text { Grandfather } \\
\text { Clause for } \\
\text { Last Change In } \\
\text { Study Period } \\
\end{array}$ \\
\hline Maine & $21-18(1972)$ & $18-20(10 / 24 / 77)$ & No \\
\hline Maryland & $21-18(1974)$ & $18-21(7 / 1 / 82)$ & YES \\
\hline Massachusetts & $21-18(1973)$ & $18-20(4 / 16 / 79)$ & YES \\
\hline Michigan & $21-18(1972)$ & $\begin{array}{l}18-19(12 / 3 / 78) \\
19-21(12 / 23 / 78)\end{array}$ & $\begin{array}{l}\text { NO } \\
\text { NO }\end{array}$ \\
\hline Minnesota & $18(N / A) * *$ & $18-19(9 / 1 / 78)$ & YES \\
\hline Mississippi & $18 / 21 *(1966)$ & -- & \\
\hline Missouri & $21(1945)$ & - & \\
\hline Montana & $18(N / A)$ & $18-19(1 / 1 / 79)$ & No \\
\hline Nebraska & $20-19(1972)$ & $19-20(7 / 15 / 80)$ & YES \\
\hline Nevada & $21(1933)$ & -- & \\
\hline New Hampshire & $18(N / A)$ & $18-20(5 / 24 / 79)$ & No \\
\hline New Jersey & $21-18(1972)$ & $\begin{array}{l}18-19(1 / 2 / 80) \\
19-21(1 / 1 / 83)\end{array}$ & YES \\
\hline New Mexico & $21(1934)$ & -- & \\
\hline New York & $18(N / A)$ & $18-19(12 / 4 / 82)$ & No \\
\hline North Carolina & $21-18 / 21 *($ CIRCA 1960$)$ & $18 / 21 *-19 / 21 *(10 / 1 / 83)$ & No \\
\hline North Dakota & $21(1936)$ & -- & \\
\hline Ohio & $18 / 21 *(1982)$ & $18 / 21 *-19 / 21 *(8 / 19 / 82)$ & \\
\hline Oklahoma & $18 / 21 *(\mathrm{~N} / \mathrm{A})$ & $18 / 21 *-21(9 / 22 / 83)$ & \\
\hline Oregon & $21(1933)$ & - & \\
\hline Pennsylvania & $21(1935)$ & - & \\
\hline
\end{tabular}

* Split legislation, first age corresponds to 3.2 beer or beer and wine, second age is for distilled liquors.

**(N/A - Not A vailable) 
Table 3: MDA History (cont)

\begin{tabular}{|c|c|c|c|}
\hline State & $\begin{array}{c}\text { MDA Change and Year } \\
\text { of Last Change } \\
\text { Pre-1975 }\end{array}$ & $\begin{array}{c}\text { MDA Change and Year } \\
\text { of Change During } \\
\text { the Study Period } \\
1975-84\end{array}$ & $\begin{array}{l}\text { Grandfather } \\
\text { Clause for } \\
\text { Last Change In } \\
\text { Study Period } \\
\end{array}$ \\
\hline Rhode Island & $21-18(1970)$ & $\begin{array}{l}18-19(7 / 1 / 80) \\
19-20(7 / 1 / 81) \\
20-21(5 / 1 / 84)\end{array}$ & $\begin{array}{l}\text { NO } \\
\text { NO } \\
\text { NO }\end{array}$ \\
\hline South Carolina & $18 / 21 *(1935)$ & $18 / 21 *-19 / 21 *(6 / 3 / 84)$ & NO \\
\hline South Dakota & $19-18 / 21 *(1972)$ & $18 / 21 *-19 / 21 *(7 / 1 / 84)$ & No \\
\hline Tennessee & $21-18(1964)$ & $\begin{array}{l}18-19(6 / 1 / 79) \\
19-21(8 / 1 / 84)\end{array}$ & $\begin{array}{l}\text { NO } \\
\text { NO }\end{array}$ \\
\hline Texas & $21-18(1973)$ & $18-19(9 / 3 / 81)$ & NO \\
\hline Utah & $21(1935)$ & -- & \\
\hline Vermont & $21-18(1971)$ & $\infty$ & \\
\hline Virginia & $18(\mathrm{~N} / \mathrm{A}) * *$ & $18-19 / 21 *(7 / 1 / 83)$ & NO \\
\hline West Virginia & $21(1934)$ & -- & \\
\hline West Virginia & $18(N / A)$ & $18-19(6 / 10 / 83)$ & YES \\
\hline Wisconsin & $21-18(197.2)$ & $18-19(7 / 1 / 84)$ & No \\
\hline Wyoming & $19(1973)$ & $-\infty$ & \\
\hline
\end{tabular}

* Split legislation, first age corresponds to 3.2 beer or beer and wine, second age is for distilled liquors.

* * (N/A - Not A vailable)

SOURCES: Direct surveying by authors, and (3) and (4). 


\subsection{POSSIBLE INFLUENCE OF MINIMUM DRINKING A GE ON FATALITIES}

The recent increases in MDA were legislated in the belief that a higher drinking age would reduce youth-involved highway fatalities because reduced alcohol consumption among this group would reduce drunk driving. Increases in MDA will not eliminate alcohol consumption altogether among affected youth because the tendency to experiment and use alcohol is strong and alcohol can be obtained illegally in several ways. The hope is that the law will convey the potential dangers of alcohol, reduce peer pressure to drink, and eliminate the serving of alcohol at social occasions. For those in this age group who still want to drink, MDA laws will raise the cost of obtaining alcohol in terms of both time and money. It will be necessary to search more, pay premiums for illegal sales, and travel greater distances. The increase in cost should reduce consumption and possibly induce more judicious use. Not only should consumption be reduced, but dangerous drinking/driving patterns such as 'bar-hopping;' driving soon after consumption, and many drunk drivers interacting at once as bars close should be reduced.

MDA laws have been criticized, however. Some people object to the abridgment of the rights of youth and the placing of taboos which may make drinking all the more intriguing. Others describe situations under which MDA laws may act as an unfavorable influence on highway fatalities even if alcohol consumption is reduced. They point to the substitution of drinking in cars (turning 'cars into bars') for on-premise drinking under supervision, the substitution of higher potency liquors for beers, more intense drinking per drinking occasion, and border crossings (creation of 'fatality alleys').

One other view is held on the MDA issue although maybe not in the extreme in which it is sometimes stated. The view is that alcohol is present in a high percentage of youthrelated fatalities -- maybe 60 percent -- but it is not the primary cause of these fatalities. Rather it is only a symptom of the real cause -- risk-taking behavior. Hence, by this view, MDA laws will not affect youth-related fatalities.

We take the position in this study that it is difficult to reason about how MDA laws actually work let alone quantify the result. It is likely that there is a net effect from the factors mentioned which impact youth who are simultaneously learning to drink and drive. Because it is difficult to reason about the effects of MDA legislation in order to forecast future results, we measure the results empirically. 


\subsection{METHODS}

Changes in MDA that have occurred in the 1975-1984 period are used to gauge the sensitivity of youth-involved highway fatalities to changes in MDA. An econometric model of fatalities involving an 18-20 year-old driver normalized by the population of that age is developed. Independent variables belleved to influence the fatality rate are tested empirically. The model uses cross-sectional observations for each of the 50 states and the District of Columbia over a ten-year period, 1975-1984, forming a pooled cross-section, time-series model estimation. All of the data available in the FARS data base at the time of this study are used in the estimation. One of the independent variables used in the model is a MDA intervention variable which specifies, for each state, the time and characteristics of any MDA change during the study period. It is the coefficient of this variable which is the statistical estimate of the sensitivity of youth-involved fatalities to MDA increases. The sensitivity is then applied to the MDA status in each state in 1984 to estimate how many lives could have been saved if each state had had a MDA of 21 years old. The lives affected in 1984 are taken as an estimate of what would happen if all states adopt a uniform MDA of 21 years old.

\subsection{Selecting a Fatality Event}

Up to this point, we have described the fatalities affected by MDA law increases as 'youth-involved fatalities' or by the longer phrase 'fatalities involving an 18-20 year-old driver.' In this subsection, we give a precise definition to these terms, show what their relationship is to other fatalities and, most importantly, discuss the reasons for their selection.

Since the primary purpose of this study is to determine the effect of a national, uniform MDA on the total number of fatalities in the United $S$ tates in a year, a fatality measure is needed which is sensitive to any changes resulting from the MDA change and which can be used to estimate the full national effect. Because we plan to estimate the effect of the MDA change empirically, we do not need to know that eliminating alcohol would eliminate the fatal accident. All we need to know is that there is a chance that a change in MDA would alter the conditions which led to the fatal accident.

Ideally, the fatalities in accidents where an 18-20 year-old driver had a positive blood alcohol level would be used to estimate the effect. However, driver blood alcohol level 
is not reliably reported in FARS; and increases in the MDA would be likely to correspond to increases in reporting. Further, since increases in reporting can only increase the number of reported fatal accidents involving alcohol, basing the analysis on fatalities in alcohol-involved accidents involving 18-20 year-old drivers is likely to produce misleading results. Without using direct evidence on alcohol involvement, there is a trade-oif between having a fatality measure which can adequately be translated into a total impact, and a measure which is sensitive and logically related to prospective MDA effects.

As an example of this trade-off, consider single-vehicle, nighttime, male fatalities which are often used as a surrogate or proxy for alcohol-related fatalities. Singlevehicle, nighttime fatalities involving male 18-20 year-old drivers should be very sensitive to changes in MDA. However, a MDA change will affect many more highway accidents than these. So, this measure has little utility in measuring the total effect of a national uniform MDA of 21 years old.

At the other extreme, if all highway fatalities were used as the dependent variable, another problem is created. The statistical estimation will not properly detect the effects of MDA increases because too much variation exists for the fatalities which are conceptually different from those affected by MDA. This variation can swamp any effects of MDA increases.

In this study, we have tried to choose a fatality series that is sensitive to MDA increases yet permits the full effect of a MDA on highway fatalities in the United $S$ tates to be measured. We have selected fatalities in all accidents which involve an 1820 year-old driver. As Table 4 shows, these fatalities were 17.6 percent of all highway fatalities in the United $S$ tates for 1984 . Table 4 also shows the per capita fatality rate and a comparison to the rates of the two adjacent age cohorts. (Notice that these fatality rates are not measured in the usual way, and since they measure all fatalities in accidents involving a driver in the age group, the fatalities involving 18-20 and 21-23 year-old drivers are not mutually exclusive.) 
Table 4: Comparison of F atalities Involving 18-20 Year-Old Drivers With Those Involving Younger and Older Drivers

\begin{tabular}{|c|c|c|c|c|c|c|}
\hline \multirow[t]{2}{*}{ Year } & \multicolumn{3}{|c|}{$\begin{array}{cc}\text { A) Fatalities } \\
\text { Involving Drivers } \\
\end{array}$} & \multicolumn{3}{|c|}{ B) $\begin{array}{c}\text { Population } \\
(000 \mathrm{~s})\end{array}$} \\
\hline & $14-17$ & $18-20$ & $21-23$ & $14-17$ & $18-20$ & $21-23 *$ \\
\hline 1975 & 4,551 & 8,996 & 7,628 & 16,932 & 12,415 & 11,623 \\
\hline 1976 & 4,725 & 9,512 & 7,913 & 16,892 & 12,634 & 11,890 \\
\hline 1977 & 5,138 & 10,108 & 8,635 & 16,782 & 12,771 & 12,139 \\
\hline 1978 & 5,091 & 10,692 & 9,126 & 16,649 & 12,764 & 12,415 \\
\hline 1979 & 4,958 & 10,551 & 9,294 & 16,275 & 12,808 & 12,634 \\
\hline 1980 & 4,651 & 10,137 & 9,055 & 16,247 & 13,091 & 12,771 \\
\hline 1981 & 4,115 & 9,160 & 8,579 & 15,574 & 12,898 & 12,764 \\
\hline 1982 & 3,358 & 7,976 & 7,744 & 14,962 & 12,599 & 12,808 \\
\hline 1983 & 3,305 & 7,445 & 7,210 & 14,633 & 12,396 & 13,091 \\
\hline \multirow[t]{2}{*}{1984} & 3,478 & 7,797 & 7,563 & 14,707 & 12,043 & 12,898 \\
\hline & \multicolumn{3}{|c|}{$\begin{array}{l}\text { C) } \\
\text { Fatalities Per Capita }(100,000)\end{array}$} & \multicolumn{3}{|c|}{ Percent of All Fatalities } \\
\hline Year & $14-17$ & $18-20$ & $\underline{21-23}$ & $14-17$ & $18-20$ & $21-23^{*}$ \\
\hline 1975 & 2.7 & 7.3 & 6.6 & 10.2 & 20.2 & 17.1 \\
\hline 1976 & 2.8 & 9.5 & 6.7 & 10.4 & 20.9 & 17.4 \\
\hline 1977 & 3.1 & 7.9 & 7.1 & 10.7 & 21.1 & 18.0 \\
\hline 1978 & 3.1 & 8.4 & 7.4 & 10.1 & 21.2 & 18.1 \\
\hline 1979 & 3.1 & 8.2 & 7.4 & 20.7 & 18.2 & 9.7 \\
\hline 1980 & 2.9 & 7.7 & 7.1 & 19.8 & 17.7 & 9.1 \\
\hline 1981 & 2.6 & 7.1 & 6.7 & 8.3 & 18.6 & 17.4 \\
\hline 1982 & 2.2 & 6.2 & 6.1 & 7.6 & 18.1 & 17.6 \\
\hline 1983 & 2.3 & 6.0 & 5.5 & 7.8 & 17.5 & 16.9 \\
\hline 1984 & 2.4 & 6.5 & 5.9 & 7.9 & 17.6 & 17.1 \\
\hline
\end{tabular}

* Derived by lagging 18-20 year-old population three years. 
Table 5: Youth Population

$\begin{array}{lcccccc}\text { Year } & \begin{array}{c}\text { Year Olds } \\ (\text { O000s) }\end{array} & \begin{array}{c}\text { Percent } \\ \text { of Total }\end{array} & \begin{array}{c}18-20 \\ \text { Year Olds } \\ \text { (000s) }\end{array} & \begin{array}{c}\text { Percent } \\ \text { of Total }\end{array} & \begin{array}{c}\text { 21-23* } \\ \text { Year Olds } \\ \text { (000s) }\end{array} & \begin{array}{c}\text { Percent } \\ \text { of Total }\end{array} \\ 1975 & 16,932 & 8.0 & 12,415 & 5.8 & 11,623 & 5.5 \\ 1976 & 16,892 & 7.9 & 12,634 & 5.9 & 11,890 & 5.5 \\ 1977 & 16,782 & 7.8 & 12,771 & 5.9 & 12,139 & 5.6 \\ 1978 & 16,649 & 7.6 & 12,764 & 5.9 & 12,415 & 5.7 \\ 1979 & 16,275 & 7.4 & 12,808 & 5.8 & 12,634 & 5.7 \\ 1980 & 16,247 & 7.2 & 13,091 & 5.8 & 12,771 & 5.6 \\ 1981 & 15,574 & 6.8 & 12,898 & 5.6 & 12,764 & 5.6 \\ 1982 & 14,962 & 6.5 & 12,599 & 5.4 & 12,808 & 5.5 \\ 1983 & 14,633 & 6.3 & 12,396 & 5.3 & 13,091 & 5.6 \\ 1984 & 14,707 & 6.2 & 12,043 & 5.1 & 12,898 & 5.5\end{array}$

* Derived by lagging 18-20 year-old population three years.

SOURCE: U.S. Bureau of Census, Current Population Reports, Series P-25.

\subsection{Adjusting for Population Changes}

Having selected the fatality event series, fatalities involving an 18-20 year-old driver, the process of apportioning the variation in the series can begin. Table 5 gives population changes for the 18-20 year-old cohort as well as the adjacent cohorts. The 18-20 year-old population increased in size from 1975-1980 then declined eight percent over the next four years. It also changed relative to the entire population. Any analysis of the highway fatalities for this age group should take into account changing population. The timing of the decline is particularly important for the study of MDA issues because during the 1980-1984 period, 26 of the 35 MDA changes in the United $S$ tates occurred during that period. The decline in population should in itself reduce 1820 year-old, driver-involved fatalities because less people are exposed. This natural reduction in these fatalities could create bias in the direction of finding a positive effect of MDA laws or an overstatement of that effect. This potential for bias is particularly important if a comparison methodology is being used where, say, the time period is split into 'before' and 'after' near 1980. The growth of 18-20 year olds will 
tend to increase fatalities in the pre-1980 period while it will tend to decrease fatalities in the after period, making the comparison biased in the direction of finding positive MDA effects.

Since this study uses state level data, the consideration of population is doubly important because within the aggregate 18-20 year-old population trend that peaks in 1980 are specific state population shifts. Some states are gaining population while others are losing. Further, there are large population differences among states which affect the fatality levels for the state for all age groups.

In this study, we have controlled for the effects of population by dividing fatalities involving an 18-20 year-old driver by the population of that age group. By normalizing a per capita fatality rate is formed. The per capita fatality rate is used as the dependent variable in a multiple regression model with other variables, many also in rate form, serving as independent variables.

Two other measures of exposure to highway accidents would have been used to normalize fatalities if they were available. The number of miles driven by 18-20 yearold drivers would be ideal. However, it is not tabulated by driver age and state. The closest variable available is total vehicle miles travelled (VMT) for all drivers. The other measure is the number of 18-20 year-old registered drivers. It would be somewhat better than population as a normalizing factor because the proportion of 1820 year olds which drive varies among states. Data on licensed drivers by age and state is only approximated for several states and therefore may give misleading results.

\subsection{Methodology}

To determine the sensitivity of fatalities to increases in the MDA, an econometric model is constructed using pooled cross-section, time-series data. The model measures the effect of changes in MDA while controlling for other factors which affect fatalities (such as economic activity). Annual fatality rates for each state and the District of Columbia represent the units of observation of the dependent variable. These 51 crosssectional units are observed over a ten-year period, 1975-1984. 1984 is the last year of full reporting in FARS which was avallable at the time of this study. The ten years of cross-sectional values provide $\mathbf{5 1 0}$ observations on which to construct a model of the effect of MDA changes. The independent variables are state observations of economic 
activity, driving activity, beer consumption, and other factors which theoretically should affect 18-20 year-old, driver-involved fatalities.

Construction of a pooled cross-section, time-series econometric model draws upon the methodologies of intervention analysis and panel studies. Panel studies are characterized by a relatively large cross-sectional number of units compared to the number of times the set is observed. A large number of cross-sectional units allows for an adequate statistical sample to be built up after only a few years of time. The quick achievement of a significant sample allows for the timely evaluation of an activity affecting the 'panel,' a feature which is desirable for studying MDA issues. A rich body of literature exists, especially from sociology and political science, on methodologies for use in panel studies (see Reference 5). Detailed statistical procedures have also been developed for panel studies, especially techniques for dealing with the complicated regression error structures that some of these models have. Work has also been done in developing the methodology for intervention analyses. Thought must be given to spliting the sample at some point before and after, and to controls for standardizing the before and after period.

Using a pooled cross-section, time-series model has several advantages over the usual method of comparing a 'before' and 'after' MDA period:

- staggered intervention (not all states change at the same time) can be modeled;

- explicit control and identification can be given to other factors which affect fatali ties:

- use of all information available will provide for efficient estimation; and

- prediction of actual fatality levels for a state is possible as well as percentage impact.

\subsection{Youth-Involved Fatality Model}

The pooled cross-section, time-series econometric model used to test the sensitivity of fatalities to increases in MDA is shown in Table 6. The dependent variable is a fatality rate, the number of fatalities involving 18-20 year-old drivers for each state divided by the population of that age group for the state. Thus, a fatality rate is formed for each state and D.C. for each of ten years over the period, 1975-1984. The natural logarithm is taken of this rate as it is for all other variables except the MDA intervention 
variable, AGE, which is measured in discrete terms. Variables are transformed to natural logarithms because percentage changes, not absolute changes, are important. $W$ ith the variables in logarithmic form the regression coefficients $(B 1, B 2, \ldots B N)$ can be interpreted as percentage sensitivities. If, for instance, $B I$ is equal to .11 , a one percent change in the $B 1$ independent variable will produce a 0.11 percent change in the fatality rate, the dependent variable.

\section{Table 6: Econometric Model to Estimate Effects of Increases in MDA}

$$
\begin{aligned}
& \log /(18-20 \ldots \text { fatalities } / 18-20 \ldots \text { population }) i t= \\
& \left.\quad \text { BO + BI } * A \text { GE }_{i t}+\text { B2... BN } * \text { LOG (INDEPENDENT VARIABLES } i t\right)+U_{i t}
\end{aligned}
$$
where:

$\mathrm{BO}=$ constant term

$\mathrm{B} 1, \mathrm{B2}, \ldots \mathrm{BN}=$ regression coefficients

$A C E=M D A$ intervention variable measuring timing and extent of change INDEPENDENT VARIABLES = variables used to control for other factors affecting fatalities

$U_{i t}=$ Stochastic error term

$i=1 . . .50$ states + D.C.

$t=1975$... 1984

The MDA intervention variable, AGE, is ' $O$ ' until the year when a state changes the MDA. The variable is ' $l$ ' if the state increases the MDA for beer of any alcoholic content from 18-21 on January 1 , and it is ' 1 ' for all years thereafter. Changes which affect fewer driver-years are captured by values of the A GE variable below '1.'

Beer of any alcoholic content was chosen as the decisive drink because previous work $(1,2)$ by the authors on socio-economic influences on highway fatalities, found changes in the consumption of beer to be statistically more significant than changes of consumption of wine or liquor, and our a priori expectation is that beer is the major alcoholic drink of 18-20 year-olds. Three characteristics of a state's MDA law change affect the value of the $A G E$ variable: the extent of change, the time of enactment, and whether or not people who legally drink at the time of enactment can continue to drink legally, 'grandfathering.' Each of these characteristics is discussed below. 
(1) Extent of Change. As Table 3 indicates, when states started to increase their MDA in 1976, the states did so from different ages. Some were 18, others 19, or 20. Further, when a state did increase its MDA, it did not necessarily increase it all the way to 21 years old. Thus, the extent of the MDA change is different among states and the effect will be different because different proportions of driver-years will be affected. In adjusting for the differences in the extent of the MDA change, we have assumed that each year the MDA is changed is equal. The result of this assumption is that the AGE variable is coded: ' 1 ' for an increase in MDA of the full three years from 18 to 21 years old; '.666' for a two-year increase; and '.333' for a one-year increase. So, an increase among younger drivers, say, 18-19 years old, is treated the same as an increase in MDA among relatively older drivers, 20 to 21 years old.

(2) Time of Enactment. Not all MDA age increases in the period under study were enacted at the beginning of the calendar year. Many enactments occurred in July and September. So, it is necessary to weight or prorate the MDA intervention variable because a full year of implementation should have more of an effect than a partial year. A $1 / 12$ weighting is given for each full month of enactment. A half year of enactment would have a 6/12 or .5 weighting and a full year, of course, a $12 / 12$ or 1 weighting. This assumes that each month has $1 / 12$ of the year's fatalities involving 18-20 year-old drivers.

(3) Grandfathering. In enacting MDA legislation, many states have not taken away the right to purchase alcohol from those who could legally do so prior to enactment. If a 20 year-old MDA age was enacted when the present MDA was 19 years old, 'grandfathering' would allow those 19 years old at the time of enactment to continue to purchase after enactment but anyone becoming 19 years old after enactment would be prohibited. The values of the MDA intervention variable are adjusted for the average percentage of drivers who are excluded during the year. In the case above, assuming an equal distribution of birthdays over the year, an average of one-half of those who are 19 years old during the year of enactment would be able to drink. The half not able to drink would be those who were 18 years old at the time of enactment. 
The MDA intervention variable is coded with a value for each state and D.C. for each of ten years. If, for instance, a state increased its MDA for the purchase of beer from 20 to 21 years old effective January 1,1980 , and if persons 20 years old on January 1 , 1980 retain the right to consume, then the MDA intervention variable would be coded ' 0 ' for each year until 1980 when it would be calculated as .167 . This 1980 value is calculated as .333 for a one-year increase in the MDA, multiplied by $12 / 12$ for a full year of implementation, and finally multiplied by .50 because on average only half of the 20 year olds were excluded during the year. In. 1981 , all 20 year olds would be excluded and the value would be .333. The values of the intervention variable for each year for this hypothetical state are:

$\begin{array}{lr}\text { Year } & \text { Value } \\ 1975-1979 & 0 \\ 1980 & .167 \\ 1981-1984 & .333\end{array}$

Essentially, the MDA intervention variable represents the differentiation among periods of the amount of exposure that $18-20$ year-old drivers have to the alcohol.

Table 7 shows the summation of all state values to the MDA intervention variable for each year. If all states and D.C. changed the MDA from 18 to 21 , the sum would total 50. State changes which affect fewer or no driver-years result in lower sums. As mentioned before, the concentration of increases in MDA comes in the latter years. Because this period has a major decline in all highway fatalities (13.4 percent from 1980-1984), it is especially important to control for other factors affecting 18-20 yearold, driver-involved fatalities in order to properly identify the effect of the MDA change.

\section{Control Variables}

Increases in the MDA are not the only factors which have the potential to cause a state's fatalities involving 18-20 year-old drivers to change over time. Nor is the MDA status of a state sufficient to explain differential fatality rates among states for the same period. Socio-economic variables and other variables measuring exposure to highway accidents are used in this study to explain variation in fatality rates. Table 8 
shows the variables that were tested for statistical significance as well as the a priori direction of influence. Most of these variables are tested and used as a rate or ratio, the latter of which is formed by the combination of two variables. For instance, an important ratio variable was formed by dividing rural VMT by total VMT. This ratio is statistically significant in explaining why fatality rates differ among states, probably because more rural driving causes greater risk.

Table 7: Concentration of 'A ge' Intervention Variable

\begin{tabular}{cc} 
Year & $\begin{array}{c}\text { Summation of } \\
\text { State Values }\end{array}$ \\
\cline { 2 - 2 } 1975 & 0 \\
1976 & .060 \\
1977 & .388 \\
1978 & 1.069 \\
1979 & 3.664 \\
1980 & 5.579 \\
1981 & 6.994 \\
1982 & 7.336 \\
1983 & 9.053 \\
1984 & 13.269
\end{tabular}

In doing any type of econometric modeling it is of ten the case that desirable information simply is not collected. Often the best that can be done is to use a proxy or surrogate for the missing concept. Hopefully the proxy is conceptually close. In modeling youth-related fatalities, there is desirable data that is not tabulated. There is no VMT for 18-20 year-old drivers, no alcohol consumption by 18-20 year olds. Even unemployment on a state basis is not consistently collected for this age group. In this study we have used measures for all the population as proxies for many of the concepts which should be measured for just 18-20 year olds. Obviously, this is a limitation; subsection 4.5 describes a technique for using dummy variables to protect against poor proxies and for omitted variables as well. 
Table 8: Control Variables

Concept

Driving

Demography

Economic

Geographic

Alcohol

Safety

Social
Variables

VMT

Rural V MT

Youth Population

All Registered Drivers

Unemployment Rate

Personal Income

Land Area

A verage A nnual T emperature

Liquor Consumption

Beer Consumption

Spending* on A lcohol P rograms

Spending* on Highway Safety

Stolen Cars
Expected

Influence on

Youth-Related

Fatalities

\section{p}

$\mathbf{P}$

P

$\mathbf{P}$

$\mathbf{N}$

$\mathbf{P}$

P

$\mathbf{P}$

$\mathbf{P}$

$\mathbf{P}$

$\mathbf{N}$

$\mathbf{N}$

$\mathbf{P}$

* From Highway T rust F unds.

$\mathbf{P}=$ Positive

$\mathbf{N}=$ Negative

\subsection{Covariance Model}

Table 9 indicates a wide variation in the fatality rate among states for 1984. Because only part of this variation can possibly come from differences in MDA, it is important to account for the state-to-state differences so that these differences are not falsely attributed to changes in MDA. Dummy variables are used to make sure the econometric model accounts for the average state-to-state and year-to-year differences in the fatality rate. This technique of adding dummy variables to other independent variables is known as the construction of a covariance model. Two different sets of dummy variables are added because of the pooled cross-section, time- 
series data structure used. One set of dummy variables tests for omitted effects which cause variation in the youth-related fatality rate among states for any one year. The other set of dummy variables check for factors such as economic activity which cause the rates of states to change or cycle over time.

These two sets of dummy variables will help protect against a common problem in econometrics, the omitted variable problem. If an important variable is omitted from a regression equation, the significance and interpretation of other included variables can be spurious or inflated. Since the purpose of this study is to estimate the sensitivity of fatalities to MDA increases, it is important that any equation expressing that relationship be properly and fully specified so that the significance of the MDA variable is not misjudged. Using dummy variables in a covariance model is a precaution against this misinterpretation.

Table 9: Fatality Rates for 18-20 Year-Old Drivers By State for 1984

(Fatalities Per 100,000 of 18-20 Year-Old Population)

$\begin{array}{lllr}\text { A labama } & 78 & \text { Montana } & 132 \\ \text { Alaska } & 97 & \text { Nebraska } & 53 \\ \text { A rizona } & 97 & \text { Nevada } & 70 \\ \text { Arkansas } & 91 & \text { New Hampshire } & 71 \\ \text { California } & 69 & \text { New Jersey } & 42 \\ \text { Colorado } & 61 & \text { New Mexico } & 89 \\ \text { Connecticut } & 67 & \text { North Carolina } & 74 \\ \text { Delaware } & 63 & \text { New York } & 42 \\ \text { District of Columbia } & 26 & \text { North Dakota } & 64 \\ \text { Florida } & 91 & \text { Ohio } & 55 \\ \text { Georgia } & 75 & \text { Oklahoma } & 71 \\ \text { Hawaii } & 40 & \text { Oregon } & 82 \\ \text { Idaho } & 77 & \text { Pennsylvania } & 51 \\ \text { lllinois } & 49 & \text { Rhode Island } & 33 \\ \text { Indiana } & 55 & \text { South Carolina } & 83 \\ \text { lowa } & 64 & \text { South Dakota } & 58 \\ \text { Kansas } & 68 & \text { Tennessee } & 87 \\ \text { Kentucky } & 58 & \text { Texas } & 76 \\ \text { Louisiana } & 73 & \text { Utah } & 58 \\ \text { Maine } & 90 & \text { Vermont } & 107 \\ \text { Maryland } & 39 & \text { Virginia } & 58 \\ \text { Massachusetts } & 48 & \text { Washington } & 64 \\ \text { Michigan } & 59 & \text { West Virginia } & 86 \\ \text { Minnesota } & 61 & \text { Wisconsin } & 69 \\ \text { Mississippi } & 86 & \text { Wyoming } & 132 \\ \text { Missouri } & 75 & & \\ & & & \end{array}$




\subsection{Estimating Lives Saved}

Using econometric models with proper controls provides an estimate of the percent change in fatalities resulting from increases in MDA. This estimation is the first stage in determining the number of lives saved if all states enact a MDA of 21 years old. In this study we use a series of steps to calculate lives saved. These lives saved are determined within the framework of what would have happened to highway fatality levels in 1984 had the MDA changed in specific states. Fatality savings can be calculated for any prior year or for any future year using the methodology of this study. To calculate the effect in a future year, it is necessary to make assumptions and forecasts about many of the variables in the model. We selected 1984 as the year to compute lives saved so that it would not be necessary to make projections of higher variables in the model. Inferences can be made about fatalities in future years from the 1984 calculations.

Lives saved in 1984 are calculated from two perspectives. First, how many lives were saved because the states already had MDAs above 18 years old in 1984, and, second, how many additional lives would have been saved if all states had increased their MDA to 21 years old in 1984 ?

In order to determine how many lives have been and could be saved within this framework, it is necessary to calculate the existing 'effective' MDA for each state in 1984. A state's MDA may have legally increased, say, to 20 years old, but for most of the year 19 year olds could still legally consume alcohol because the law was grandfathered and/or because the law was passed late in the year. If increases in MDA reduce fatalities, then, all other things being equal, this state should have comparable fatality count than a state having a MDA of 20 years old throughout the year. The 'effective' MDA accounts for these considerations so that the fatalities in each state can be classified consistently as to the MDA conditions under which 1984 fatality levels actually occurred.

An example makes this clearer. In 1984, 245 people died in accidents involving 18-20 year-old drivers in Georgia. The legal age to purchase beer in Georgia was increased to 20 years old on September 30, 1984. It had been 19 years old. For most of the year, 
Georgia's MDA was 19 years old. However, for one-quarter of the year (September 30December 31), 19 year olds would not have been affected by a hypothetical change in MDA to 21 years old because they were affected by the actual law change in Georgia. Since we want to use driver-years as a proxy for accidents, we want to count one-fourth of the one-third of all 18-20 year-old driver-years which are 19 year olds as not being affected by the hypothetical MDA change. So, $1 / 4 \times 1 / 3=1 / 12$ of the 245 Georgia fatalities should be classified as not affected (like a state with a MDA of 21), and 11/12 should be classified as affected as a state with a MDA of 19 years old. While this calculation is rather involved, particularly for states which grandfathered changes, it is essential to accurately account for likely effects of changes in the MDA. 


\subsection{RESULTS}

This section reports the results of estimating the sensitivity of fatalities to increases in MDA fatalities and presents the implications of this sensitivity in terms of lives saved.

\subsection{Fatality Sensitivity to MDA Changes}

In order to estimate the sensitivity of 18-20 year-old, driver-related fatalities to increases in MDA during the 1975-84 period, a series of four pooled cross-section, timeseries multiple regression models were constructed. The four models represent steps taken to find the best estimate of sensitivity and to protect against any spurious interpretation. In the first few models tested, the protection against omitted variables is not strong enough. In the last few models tested the protection is probably overdone, causing a collinearity among included variables.

Table 10 shows the best model that can be constructed without the covariance model structure using only available socio-economic and activity driving data. It is best in the sense of having theoretically important variables which are statistically significant and which explain more of the variation than other models. (Table 11 gives the definitions of the variables used in this and subsequent models.) The t-statistics for the variables are given in parentheses directly below the coefficient values. These coefficients are interpreted as producing a percentage change in the dependent variable, the fatality rate because the variables are in natural logarithmic form. To insure that undue influence is not exerted by states with relatively small numbers of fatalities, statistical estimation is done by Weighted Least Squares (WLS) as well as Ordinary Least Squares (OLS). In the WLS estimation, fatalities are used to weight the state-year observed.

As indicated by the adjusted R2 (ADJ.R2), Model I explains between 40 to 60 percent of the variation in the fatality rate depending upon whether WLS and OLS estimation is used. The coefficient of the MDA intervention variable, $A G E$, is -0.19 and -0.26 for WLS and OLS estimation, respectively. This means that a change in the MDA from 18 to 21 will produce a change in fatalities involving 18-20 year-old drivers of between 19 and 26 percent (depending on method of estimation). 
Model 1, shown in Table 10 (variables defined in Table 11), indicates that fatalities involving 18-20 year-old drivers are correlated negatively with the unemployment rate which was expected from previous studies $(1,2)$. The consumption of beer is positively associated with youth-related fatalities as is the percentage of rural VMT. Both these outcomes meet a priori expectations. All of the variables in Model 1 are statistically significant at the one percent level as indicated by the t-statistics.

Many other variables were tried as well as different specifications of the included variables, but Model I was the 'best' in terms of theoretical expectations, statistical significance (F-value and t-statistics), and fraction of variation explained (ADJ.R2).

Model I does have several drawbacks. First, the different estimating techniques, OLS and WLS, produce sizeable differences among coefficient values indicating that the specified model is not stable or robust. Second, only about half the variation in fatalities is explained. Third, though beer consumption affects fatalities involving 1820 year-old drivers, it is also affected by the MDA change. So, some of the MDA effect will be measured in the BEER coefficient. Finally, it is not difficult to think of other variables which, if available, should have been included in Model I. In summary, the possibility exists that important variables which also affect this group of fatalities have been left out of the model. This omission may bias the coefficients of the variables in the model including the $A G E$ variable.

To protect against the effects of an omitted variable, dummy variables are used to test and account for unexplained variation associated with either state or year. One set of dummy variables is used to test for different fatality rates among states. Since there are 50 states plus D.C. in the data set, 50 dummy variables are used to differentiate each of these units from the other. The one remaining unit is contained in part in the constant term of the regression model. Coding 51 dummy variables would produce perfect collinearity and econometric estimation would not be possible. To account for differences in fatality rates over time, a series of nine dummy variables are capable of distinguishing variations among the ten years of observations. Both these sets of discretely coded dummy variables (coded $10^{\prime}$ or ' 1 ') will not of course identify the causes of the variation. The dummy variables will only account for it. However, the technique of using these variables in the construction of a covariance model is useful for a situation like the MDA issue where not all explanatory variables are avallable or known. 


\section{Table 10: Model I Results}

DEPENDENT VARIABLE: $18-20 . .$. FATALITIES/18-20... POPULATION

Independent $V$ ariables:

OLS*

WLS* *

CONSTANT

$-1.12$

$-1.17$

$(-3.22)$

$(-3.76)$

AGE

$-0.26$

$-0.19$

$(-4.55)$

$(-4.27)$

UNE MP.R

$$
-0.20
$$$$
-0.30
$$

$(-5.24)$

$(-9.11)$

BEER

$$
0.27
$$

0.32

$(4.40)$

(5.90)

RURAL VMT \%

$$
\begin{gathered}
0.27 \\
(24.57)
\end{gathered}
$$$$
0.29
$$

ADJ.R2

.587

.404

F-VALUE

182.19

87.21

OBSERVATIONS

510

510

ALL VARIABLES IN NATURAL LOGARITHMS

* Ordinary Least Squares.

* * Weighted Least Squares. 
Table 11: Variables Used in MDA Models

DEPENDENT VARIABLE:

Fatality Rate: Annual fatalitles for each state and District of Columbia which involve an 18-20 year-old driver divided by the 18-20 year-old population (in 000s). Fatality data is from the FARS data base as of May 29, 1985. Population data is from the U.S. Bureau of Census, "Current Population Reports," Series P-25.

INDEPENDENT VARIABLES:

AGE: MDA intervention variable. Coded '.333,' .666 ,' or ' 1 ' respectively for an increase of one, two, or three years in a state's MDA. This coded value is modified if appropriate for starting dates other than January 1 st, and for 'grandfathering' (see Section 4.4). Sources of information are direct surveying by the authors (3), and (4).

UNE MP.R: Unemployment rate for all members of the labor force. Sources are various issues of 'Employment and Earnings,' U.S. Department of Labor, Bureau of Labor Statistics.

BEER: Per capita consumption of malt beverages (in gallons). Source is 'B rewers A Imanac,' United S tates B rewers Association, Inc.

RURAL VMT \%: Ratio of rural vehicle miles of tavel to total vehicle miles of travel. Source is U.S. Department of Transportation, Federal Highway A dministration. divided by the 20 and older population. Sources are the same as 'Fatality Rate.' 
Model II, shown in Table 12, is the covariance model with just the AGE variable included with the '50 S tate Dummies of the ' $T$ Time-Series Dummies.' Some of the shortcomings of Model I have been overcome because more variation is explained and the coefficients of the two estimating techniques are closer in value.

\section{Table 12: Model II Results}

$\begin{array}{lcc} & \text { OLS } & \text { WLS } \\ \text { CONSTANT } & -0.39 & -0.36 \\ & (-6.33) & (-15.60) \\ \text { AGE } & -0.10 & -0.13 \\ & (-1.69) & (-3.57)\end{array}$

50 STATE DUMMIES

9 TIME-SERIES DUMMIES

ADJ.R2

.809

.810

F-VALUE

36.86

37.08

From previous work on highway fatalities $(1,2)$, we feel that many fatality series contain cycles, especially economic cycles. These cycles are not regular in occurrence nor necessarily similar in shape. Such cycles are not entirely modeled by dummy variables or other econometric techniques such as autoregressive and trend terms. To account for these cycles, we have added to the covariance Model II the per capita fatality rate for fatalities involving a driver over $\mathbf{2 0}$ years old. Many of the factors which affect the 18-20 year-old fatality series, the dependent variables, in a cyclical or irregular fashion, should also affect the fatality rate of the older drivers. 
This addition to the covariance model is shown in Table 13 as Model III. The WLS value of the A CE coefficient is lowered from 13 to 11 percent. The OLS estimation produces an increase in MDA sensitivity from 10 to 14 percent. We believe that the WLS method should produce the best estimate of the sensitivity because the influence of states with fewer fatalities is lessened. WLS estimation may also provide protection against heteroscedasticity. With heteroscedasticity the residuals of one group of observations have a different variance than those of other groups. Although this does not produce biased or inconsistent estimates, knowledge of different residual variances can be used to produce more efficient estimates. It is likely that the smaller fatality states have the larger error variances in an OLS estimation because the smaller fatality counts have larger random errors. Thus, we place more confidence in the 11 percent WLS estimate of the sensitivity to MDA increases.

\section{Table 13: Model II Results}

OLS

CONSTANT

0.55

(5.04)

ACE

$-0.14$

$(-2.52)$

OTHER FATALIT Y RATE

$$
0.74
$$

WLS

$-0.11$

$$
0.91
$$

50 STATE DUMMIES

9 TIME-SERIES DUMMIES

ADJ.R2 
The variables used in Model I and Model III are combined in Model IV (see Table 14). The unemployment rate for all members of the labor force is not statistically significant. We interpret this to mean that general unemployment does not affect youth-related fatalities any differently than other fatalities. Any economic effect, as determined by the unemployment rate, is contained in the older-driver fatality rate. The ratio of rural VMT to total VMT was not statistically significant. We have concluded that in Model I this ratio partly explains why youth-related fatality rates are different among states for a given year. In the covariance model, the difference among states is explained more fully by the set of state dummy variables. The per capita beer consumption variable (BEER), though statistically significant and the expected sign, has the same problem identified in Model I. Per capita beer consumption is affected by the MDA change. So, the effect of the MDA change is underestimated when BEER is also in the model. Finally, notice that the adjusted $\mathrm{R} 2$ of Model IV is almost the same as Model III. So, the extra variables contained in Model IV contribute almost nothing to our ability to explain variations in annual, state, per capita fatalities involving 18-20 year-old drivers.

The best estimate (Model III) of the sensitivity of youth-involved fatalities to changes in MDA is 11 percent. Thus, a change in MDA from 18 to 21 would cause an eleven percent reduction in a state's annual per capita fatalities involving 18 to 20 year-old drivers. This estimate is determined in Model III which explains about 88 percent of the variation in this set of annual state fatalities. Obviously, we cannot be certain that the true effect of such a MDA change is not somewhat higher or lower. We can say that the true effect of a MDA change from 18 to 21 lies between 5 percent and 17 percent at the 95 percent confidence level.

In any econometric model such as the one that produced the above results, the residuals of the regression equation, the terms which represent unexplained variation, should have desirable properties such as randomness, independence, and an approximate normal distribution. The residuals were not extensively tested for Model III. However, two common deficiencies of the residuals were considered. As mentioned above, the problem of heteroscedasticity would be reduced by WLS estimation, and by the logarithmically transformed data in the model. First-order autocorrelation of the residuals was found not to be a problem in the model. 
Table 148 Model IV Results

CONSTANT

AGE

UNEMP.R

BEER

RURAL VMT \%

OTHER FATALIT Y RÁTE
OLS

0.69

(8.69)

WLS

$$
-1.50
$$

$-1.22$

$(-1.28)$

$(-1.54)$

$-0.12$

$-0.09$

$(-2.10)$

$(-3.00)$

$-0.02$

$-0.01$

$(-0.25)$

0.36

0.37

(1.79)

(2.66)

$-0.04$

0.01

$(-0.26)$

$(0.07)$

0.86

(13.44)

SO STATE DUMMIES

9 TIME-SERIES DUMMIES

ADJ.R2

.844

.880

F-VALUE

44.06

59.46 


\subsection{Spillover Effects}

MDA law increases were found to reduce fatalities involving 18-20 year-old drivers. Before calculating the lives saved by MDA laws, we wish to consider a related issue. Does the effect spillover and effect other age groups? The models previously developed are flexible enough to test for a spillover effect.

Model III is used to test if fatalities involving 14-17 year-old drivers have changed significantly after MDA increases. The theory is that these younger drivers will also reduce their alcohol consumption because the difficulty in obtaining alcohol will be further increased by the increased MDA. Table 15 gives the results of this test. The dependent variable has been changed to the fatalities involving this younger group and the population of the younger group is used to normalize the variable. The MDA intervention variable, AGE, is not statistically significant. As Table 4 indicates, the 14-17 year-old, driver-involved fatality series is only about 55 percent of the 18-20 year

olds. Hence, there may be more 'noise' in the younger series which makes it difficult to discern any effect. To overcome this, we combined the two series into a fatality rate involving 14-20 year-old drivers. Table 16 shows the results of this test. The AGE variable is statistically significant. The coefficient of the $A G E$ variable indicates a sensitivity of about seven percent for a full three-year MDA increase. The combined fatality series is three times as large as the younger series and it contains, of course, the 18-20 year-old, driver-involved fatalities which have been shown to be sensitive to MDA changes. However, the coefficient reduction (11 percent to 7 percent) is directly proportional to the increase in the population covered in the dependent variable. So, the estimated lives saved using the 18-20 year olds model is the same as the estimated lives saved using the 14-20 year olds model. Therefore, none of the lives saved can be attributed to the effects of the MDA on accidents involving 14-17 year-old drivers. From this evidence, we conclude that there is no statistical evidence of a spillover effect from MDA increases to the younger cohort.

It has been argued that even if raising the MDA reduces 18-20 year-old driver-involved fatalities, there is an increase in fatalities among those slightly older than 21 years old. It is argued that fatalities are postponed until a time when drivers begin to drink. Postponing legal drinking will only postpone fatalities because initial experience with alcohol is particularly dangerous no matter when it occurs. To test this hypothesis, a dependent variable was constructed for the fatality rate involving 21-23 
Table 15: Model III on 14-17 Year-Old Drivers

Dependent Variable: 14-17 ... Fatalities/14-17 . .. Population

Independent $V$ ariables:

CONSTANT

OTHER FATALIT Y RATE

(21+ years old)

50 STATE DUMMIES

9 TIME-SERIES DUMMIES

ADJ.R2

F-VALUE

Variables in Natural Logarithms.
WLS

$-0.51$

$(-4.75)$

0.005

$(0.12)$

0.69

(8.66)

.873

58.41 
Table 16: Model III on 14-20 Year-Old Drivers

Dependent Variables 14-20 ... Fatalities/14-20 . . Population Independent $V$ ariables:

WLS

CONSTANT

0.24

(3.95)

AGE

$-0.07$

$(-2.97)$

OTHER FATALIT Y RATE

0.83

$(21+$ years old)

$(18.43)$

50 STATE DUMMIES

9 TIME-SERIES DUMMIES

ADJ.R2

F-VALUE

110.25 
year-old drivers. A new MDA intervention variable, AGEX, was also constructed as a variation of the variable $A G E$. A period of time has to elapse from the time an MDA law is passed in a state to the time when those affected become 21 years old and older. Because most of the MDA law changes occurred recently, there are few values for $A$ GE $X$ for most of the states.

The results of this spillover test are shown in Table 17. Model II is used. It is the same as Model III except that it excludes the other fatality rate. Since this other fatality rate includes 21-23 year-old drivers, the dependent variable, it is inappropriate in this test. The AGEX variable is not significant and the sign is opposite that argued above. From this evidence, we conclude that there is no statistical evidence for the hypothesis of fatalities being postponed by MDA legislation. However, we feel that enough time has not elapsed to fully evalua te this hypothesis.

One final test was made of the power of these models to discern precisely that effect which is being examined -- the effect of increases in MDA on fatalities. The MDA variable should not pick up the effects of other safety programs or trends. By testing Model II with the ACE variable and a different fatality rate for a dependent variable, it can be determined if the $A G E$ variable measures what it should. The fatality rate used in the test is that for 21-23 year-old, driver-involved fatalities which should be affected by many of the forces that effect the 18-20 year olds but should be not directly and concurrently effected by MDA law changes. Table 18 shows the result. The ACE variable is not significant while referring back to Table 12 shows its importance in explaining the fatality rate involving 18-20 year old drivers. This test demonstrates the precision of these models in identifying and measuring the effect of MDA changes.

\subsection{Estimating Lives Saved}

Now that an estimate of the sensitivity of annual state fatality rates to MDA increases is available, the lives saved can be calculated. As previously mentioned, our primary purpose in this study is to determine what the effect will be if all states in the U.S. adopt a 21 year-old MDA. To make this determination, an estimate is made of the number of fatalities involving 18-20 year-old drivers which would not have occurred if all states had a 21 year-old MDA in 1984. That is, if states which had an MDA of less than 21 years old raised it to 21 , effective January 1, 1984, how many fewer lives would have been lost in 1984. 
Table 17: Model II on 21-23 Year-Old Drivers

Dependent Variable: 21-23 ... Fatalities/21-23 ... Population

Independent V ariables:

wLS

CONSTANT

$-0.29$

$(-12.76)$

$-0.12$

ACEX

$(-1.49)$

50 STATE DUMMIES

9 TIME-SERIES DUMMIES

ADJ.R2

0.814

F-VALUE

38.10 
Table 18: Statistical Test of AGE Using

Model II on 21-23 Year-Old Drivers

Dependent Variable: $21-23$... Fatalities/21-23 ... Population

Independent $V$ ariables:

OLS

WLS

CONSTANT

$-0.29$

$-0.32$

$(-4.36)$

$(-12.74)$

AGE

$-0.02$

$-0.05$

$(-0.31)$

$(-1.28)$

SO STATE DUMMIES

9 TIME-SERIES DUMMIES

ADJ.R2

F-VALUE

30.86

38.04 
In addition to estimating the lives which might have been saved in 1984, we also estimate the present effect of MDA laws above 18 years old. By this we mean the increase in lives lost in 1984 if all states had a MDA of 18.

In the following calculations, -11 percent is used as the sensitivity of fatalities to MDA changes from 18 to 21 . For states with a MDA of 19 years old, the sensitivity would be .666 of the -11 percent or about -7 percent. For states with a MDA of 20 years old, the sensitivity would be .333 of the -11 percent or about -4 percent. In calculating the lives saved already by any MDA above 18 years old, the different sensitivity changes are applied to the age groups in reverse because the sensitivity is measured from existing fatality levels in either direction. That is, +11 percent is used to estimate the effect of a roll back from 21 to 18 years old; +7 percent for 20 to 18 ; and +4 percent for 19 to 18 .

Before applying these sensitivities to the actual number of 1984 fatalities which occurred in each state, an adjustment needs to be made for partial MDA effects. For some of the states, 1984 was a year of transition because new MDA's were established after the beginning of the year and/or grandfathering was in effect. We have used a procedure much like that of determining the value of the MDA intervention variable, AGE. The percentage of the time during the year that a new MDA law was in effect is used to adjust the number of fatalities in each age group for each state. The consideration of these partial effects creates fatality counts which can be used with the appropriate MDA sensitivity percentage to calculate the effects of MDA changes. Table 19 shows these adjusted fatality totals for states grouped by effective MDA for 1984. The effective MDA aggregation of fatalities is very similar to a summing by groups of states with the same legal MDA. The only real difference is that for a few states, the MDA which was in force for most of the year is selected instead of the present legal MDA. This adjustment groups fatalities for calculating lives saved easily without distorting the results.

In determining the lives saved from a uniform MDA of 21 in 1984, the number of fatalities of each age group that would be affected is first calculated. Obviously, none of the 21 year-old group is affected. Only about one-third of the 18-20 year-old drivers in states with an effective MDA of 20 will be effected by an increase in MDA to 21 . This sensitivity can be expressed by saying that one-third of the 399 fatalities, or 133 fatalities, should be reduced by the 11 percent to determine the benefits to this group. 
Table 19

Effective Minimum Drinking A ges Total and A djusted Fatalities

Fatallties

Date of MDA Where Effective

State MDA-21 Change in 1984 MDA was 21

\begin{tabular}{|c|c|c|c|c|}
\hline State MDA-21 & $\begin{array}{c}\text { Date of MDA } \\
\text { Change in } 1984 \\
\end{array}$ & $\begin{array}{c}\text { Fatallties } \\
\text { Where Effective } \\
\text { MDA was } 21 \\
\end{array}$ & $\begin{array}{c}\text { A djustment } \\
\text { to (Age Group) }\end{array}$ & $\begin{array}{c}\text { Total } \\
\text { Fatalities }\end{array}$ \\
\hline Alaska & $G *(19-21) 10 / 26 / 83$ & 16.1 & $12.9(18)$ & 29 \\
\hline Arkansas & none & 103 & none & 103 \\
\hline California & none & 877 & non & 877 \\
\hline Delaware & none & 22 & none & 22 \\
\hline Illinois & none & 286 & none & 286 \\
\hline Indiana & none & 158 & none & 158 \\
\hline Kentucky & none & 112 & none & 112 \\
\hline Maryland & $G(18-21) 7 / 1 / 82$ & 63.3 & $31.7(18)$ & 95 \\
\hline Missouri & none & 284 & none & 284 \\
\hline Nevada & none & 31 & none & 31 \\
\hline New Jersey & $G(19-21) 1 / 1 / 83$ & 127.5 & $25.5(18)$ & 153 \\
\hline New Mexico & none & 68 & none & 68 \\
\hline North Dakota & none & 21 & none & 21 \\
\hline Oklahoma & none & 116 & none & 116 \\
\hline Oregon & none & 98 & none & 98 \\
\hline Pennsylvania & none & 297 & none & 297 \\
\hline Rhode Island & $(20-21) 5 / 1 / 84$ & 15.1 & $1.9(18)$ & 17 \\
\hline Tennessee & $(19-21) 8 / 1 / 84$ & 125.8 & $80.2(18)$ & 206 \\
\hline Utah & none & 51 & none & 51 \\
\hline Washington & none & 134 & none & 134 \\
\hline TOTALS & & 3,197 & $152(18)$ & 3,349 \\
\hline $\begin{array}{l}\text { A djustment fr } \\
\text { where MDA is }\end{array}$ & $\begin{array}{l}\text { rom states } \\
\text { s } 19 \\
18\end{array}$ & $\begin{array}{l}20 \\
75.0\end{array}$ & & \\
\hline A djusted Tota & & $3,292.0$ & & \\
\hline
\end{tabular}

Adjustment Total to (Age Group) Fatalities

\section{e}


Table 19

Effective Minimum Drinking Age: Total and A djusted Fatalities (cont.)

Fatalities

Date of MDA Where Effective

State MDA-20 Change in 1984 MDA was 20

A djustment to (Age Group)

Total

Connecticut

none

110

none

Fatalities

Maine

none

55

none

110

Massachusetts

none

156

none

55

Nebraska

none

42

none

156

New Hampshire none 36

none

42

TOTALS

399

0

36

399

Fatalities

Date of MDA Where Effective

A djustment

S tate MDA-19 Change in 1984

MDA was 19

to (Age Group)

Total

A labama

159

none

Fatalities

Arizona

none

160

none

159

Florida

none

445

none

160

Georgia

$(19-20) 9 / 30 / 84$

224.5

$20.4(21)$

445

Idaho

none

36

none

245

lowa

none

90

none

36

Minnesota

none

131

none

90

Montana

none

49

none

131

New York

none

381

none

49

North Carolina

none

246

none

381

Ohio

none

305

none

246

305

Texas

none

626

none

626

Virginia .

none

183

none

183

Wyoming

none

29

none

29

TOTALS

3,065

$20(21)$

3,085 


\section{Table 19}

Effective Minimum Drinking A ge: Total and A djusted Fatalities (cont.)

Fatalities

Date of MDA Where Effective

A djustment

to (Age Group). Fatalities

State MDA-18 Change in 1984 MDA was 18

Colorado

none

101

none

101

District of

Columbia

none

9

none

9

Hawail

none

23

none

Kansas

none

84

none

84

Louisiana

none

176

none

176

Mississippi

none

117

none

117

South Carolina

$(18-19) 6 / 3 / 84$

130

$21(21)$

151

South Dakota

$(18-21) 7 / 1 / 84$

18

3 (21)

Vermont

none

32

none

32

West Virginia G $(18-19) 6 / 10 / 83$

54

$22(21)$

76

Wisconsin

$(18-19) 7 / 1 / 84$

145

$29(21)$

174

TOTALS

889

74 (21)

964

A djustment from states

where age was 21

152

Adjusted T otal

1,041

Summary

Effective

Total

Fatalities

in States

S tates classified as

21

20

19

18
3,292

399

3,065

$\underline{1,041}$

7,797
3,349

399

3,085

964 
This method of calculation is equivalent to multiplying all 399 fatalities by approximately 4 percent $(.11 \times 1 / 3)$ to obtain the reduction in fatalities. Likewise, the number of fatalities in states with a MDA of 19 is determined as two-thirds of the total fatalities involving the 18-20 year-old group. All fatalities in the 18 year-old group are affected because this group would have the MDA raised three full years. Table 20 shows these calculations. Totaling the number of fatalities that would be affected $(3,217$ of the total 7,797$)$ and multiplying by the 11 percent sensitivity, we calculate that 354 lives would have been saved in 1984 if all states had had a 21 year-old MDA.

To determine the number of lives that have already been saved, the number of fatalities in each age group that could be affected is determined and is shown in the last column of Table 20. This amount, 4,580, is multiplied by the 11 percent sensitivity. The result indicates that 504 lives have been saved by MDAs greater than 18 years old.

Table 20: Measured Lives Saved in 1984 By a Uniform MDA of 21

In states where the effective Minimum Drinking A ge (MDA) is:

\section{1}

20

19

18

Total
A djusted* Total

Fatalities

3,292

399

3,065

1,041

7,797

Lives which could have been saved in 1984 if MDA were 21

$(.11 \times 3,217)$

Lives saved in states with MDA above 18 in 1984 $(.11 \times 4,580)$

Total lives saved by a change in MDA from 18 to 21
354

504
Fatalities Affected by MDA of 18

3,292

266

1,022

2,043

1,041

3,217

4,580 


\begin{abstract}
Altogether, it is concluded that 858 (354 plus 504) lives would be saved by a MDA change from 18 to 21 years old in all states. The 354 lives that would be saved by presently increasing the MDA to 21 years old in the states with MDAs below 21 in 1984 represents 4.5 percent of the 7,797 youth-related fatalities and slightly less than one percent of all fatalities.
\end{abstract}




\subsection{CONCLUSIONS}

A pooled cross-section, time-series econometric model was used to develop an estimate of the effect of uniform MDA of 21 on highway fatalities in the United States. The models of state per capita annual fatalities involving 18-20 year-old drivers explain more than 85 percent of the variation in fatality rates. The measure of the state MDA changes is selective and precise in isolating the effect of MDA changes. We feel confident that we have not credited MDA changes for changes in fatalities caused by other factors.

The best estimate of the effect of a change in MDA from 18 to 21 on highway fatalities involving 18-20 year-old drivers is 11 percent. That is, we expect highway fatalities involving 18-20 year-old drivers to decline by 11 percent if the MDA is increased from 18 to 21 . In states where the MDA is already above 18 , we expect the change in fatalities to be smaller because fewer drivers are affected by the change. In states where the current MDA is 19, we expect only two-thirds of this change in fatalities when the MDA is changed to 21. Similarly, states with a MDA of 20 are expected to experience only one-third of the change in fatalities by increasing the MDA to 21 .

Obviously, the total effect of a uniform MDA of 21 in the United 5 tates depends on the status of state MDA laws when the change goes into effect. In this study, we calculate the total United $S$ tates effect based on what actually took place in 1984. In that year, 7,797 highway fatalities involved drivers in the 18-20 age group. Based on the MDA laws in effect in the states where these fatalities occurred, we estimate that 354 lives would have been saved if those states with MDAs less than 21 in 1984 had raised their MDA to 21.

Finally, we estimate that 504 lives were saved in 1984 because many states had MDAs above 18. 


\section{REFERENCES}

1. Hoxie, Paul, David Skinner, and George H.K. Wang, "Socio-Economic Influences on Highway Fatalities: An Empirical Investigation," U.S. Department of Transportation, Transportation Systems Center, DOT-HS-806 525, a staff study:

2. Hnxie, Paul and David Skinner, "A Statistical Analysis of Socio-Economic Influences on Three Groups of High Risk Fatalities," U.S. Department of Transportation, Transportation Systems Center, FR-45-U-NHT-86-06, a staff study.

3. Wagenaar, Alexander C., Alcohol, Young Drivers, and Traffic Accidents, Lexington Books, D.C. Heath and Company, Lexington, MA, 1983.

4. The Liquor Handbook, 1984 (and previous issues).

5. Greenberg, D.F. and R.C. Kessler, Linear Panel Analysis: Models of Quantitative Change, Academic Press, New York, 1981. 




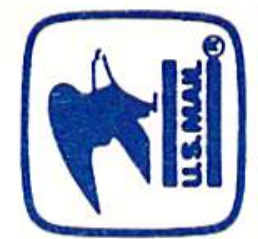

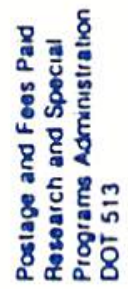

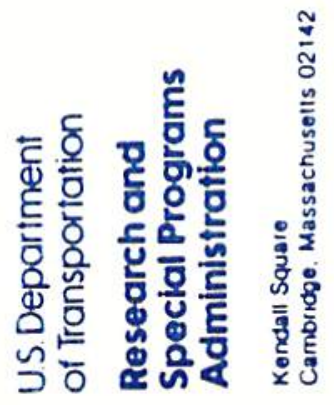

